\title{
Lewy Body Dementia
}

National Cancer Institute

\section{Source}

National Cancer Institute. Lewy Body Dementia. NCI Thesaurus. Code C84826.

A progressive form of dementia characterized by the presence of protein deposits called Lewy bodies in the midbrain and cerebral cortex, and loss of cholinergic and dopaminergic neurons. The signs and symptoms overlap with Alzheimer and Parkinson disease. 